\title{
Oral Health Research and Scholarship in 2040: Executive Summary
}

\author{
Peter J. Polverini, DDS, DMS \\ Abstract: This executive summary for Section 6 of the "Advancing Dental Education in the $21^{\text {st }}$ Century" project provides an \\ overview of five background articles that address the role of research and scholarship in dental education in the year 2040. \\ Beginning with a historical account of research and discovery science in dentistry's evolution as a profession, the article then \\ reviews the role of early thought leaders and organized dentistry in establishing research as a cornerstone of dental education and \\ dental practice. The dental research workforce faces an uncertain future fueled by a volatile funding environment and inadequate \\ mentoring and training of research faculty. Dental schools must forge stronger academic and scientific ties to their university and \\ academic health centers and will be challenged to develop sustainable research and patient care collaborations with other health \\ professions. The changing health care environment will create new opportunities for oral health care providers to expand their \\ scope of practice and focus on prevention and screening for non-communicable chronic diseases. Dental practitioners in the fu- \\ ture are likely to place greater emphasis on managing the overall health of their patients while promoting closer integration with \\ other health professionals. All dental schools must develop a sustainable research mission if they hope to graduate dentists who \\ function effectively in a collaborative health care environment. The changing scientific and health care landscape will dramati- \\ cally alter dental education and dental practice. Dental schools need to reconsider their research and educational priorities and \\ clinical practice objectives. Until dental schools and the practicing community come to grips with these challenges, a persistent \\ attitude of complacency will likely be at the dental profession's peril.
}

Dr. Polverini is Jonathan Taft Distinguished University Professor of Dentistry, Department of Periodontics and Oral Medicine, School of Dentistry, and Professor of Pathology, Medical School, University of Michigan. Direct correspondence to Dr. Peter J. Polverini, Department of Periodontics and Oral Medicine, University of Michigan School of Dentistry, 1011 N. University Ave., Rm. G020A, Ann Arbor, MI 48109-1078; 734-764-1543; neovas@umich.edu.

Keywords: dental education, research, dentistry, interprofessional practice, workforce, collaboration, health professionals

Submitted for publication 2/5/17; accepted 3/2/17

doi: 10.21815/JDE.017.070

$\mathrm{T}$ The "Advancing Dental Education in the $21^{\text {st }}$ Century" project is a strategic planning project for dental education in the U.S. This executive summary for Section 6 of the project provides an overview of five background articles addressing the role of research and discovery science in dental education and dental practice (Table 1). The articles address the following topics: issues of the historical role of research and discovery in the evolution of the dental profession; ${ }^{1}$ challenges affecting the future of the academic dental workforce and academic dentistry; ${ }^{2}$ the relationship of dental schools to research-intensive universities and academic health centers; ${ }^{3}$ the role of the dental profession and the changing practice environment in managing the overall health of patients; ${ }^{4}$ and the central role of research and discovery science in the future of dental education and practice. ${ }^{5}$

\section{Dentistry's Emergence as a Science-Based Profession}

Dentistry's origin as an empirical, apprenticebased health care discipline was transformed into a science-driven discipline because of early investments in discovery science, the introduction of new technology into the practice environment, and national advocacy efforts. Investments in research and discovery in the early part of the $20^{\text {th }}$ century played an important role in shaping the profession. ${ }^{6}$ With the formation of the American Dental Association (ADA) 157 years ago and such organizations as the American Dental Education Association (ADEA), American Association for Dental Research (AADR), National Institutes of Health (NIH), and National Institute for Dental and Craniofacial Research (NIDCR), dentistry gained respect and influence as a science-driven health care discipline. ${ }^{7}$

Dentistry's modest origins in the $17^{\text {th }}$ century in the U.S. were established by pioneers and visionary leaders who understood and advocated for the scientific basis of the dental profession. ${ }^{8}$ Dental research matured from a regional, proprietary responsibility to a nationally recognized effort that impacted the public good. The national investment in dental research has had a positive impact on the quality of life by eliminating much of the burden of dental disease. However, there continue to be significant disparities in the incidence of dental disease affecting a large 
Table 1. Titles and authors of background articles in Section 6 of this project

Title Author/s

How Research Training Will Shape the Future of Dental, Oral, and Craniofacial Research

Oral Health Care in the Future: Expansion of the Scope of Dental Practice to Improve Health

The Future of Dental Schools in Research Universities and Academic Health Centers

Research and Discovery Science and the Future of Dental Education and Practice

The Impact of Research on the Future of Dental Education: How Research and Innovation Shape Dental Education and the Dental Profession

Rena N. D'Souza and John Colombo

Ira B. Lamster and Noreen Myers-Wright

Laurie K. McCauley

Peter J. Polverini and Paul H. Krebsbach

Harold C. Slavkin

Note: See references for full citations of these articles and links to them in the online supplement.

segment of the population nationally and globally. With the development of formal dental curricula, dental school faculty members were better able to address the expanding oral health needs of a growing U.S. population. European scientists and thought leaders such as Willoughby D. Miller and Greene Vardiman Black were instrumental in establishing a link among research, scientific innovation, and education in dentistry. ${ }^{89}$ The support of research by the ADA and American Medical Association (AMA) for the public good played a central role in establishing the scientific foundations of dentistry. ${ }^{10}$

Early on, as Slavkin explains, dental research was supported primarily by private funds, but with the recognition by the federal government of the importance of research to dental practice, research funding by the federal government supplanted proprietary funding. ${ }^{1}$ The recognition by the National Dental Association (NDA) of the need to prevent caries in children led to the creation of the Indian Health Service and the NIH in 1930. In 1931, with the assistance of the ADA, the Public Health Service, and the NIH, Trendley Dean, a public health dentist, conducted the first studies of mottled enamel in the United States. His recognition of the link between children with tooth decay and mottled enamel and fluoride levels in the drinking water led to his clinical trial in Grand Rapids, Michigan, of fluoride in preventing caries. The study of the role of fluoride in preventing dental caries is considered by many to be the most important public health advance in the $20^{\text {th }}$ century. Research such as this positioned the dental profession as an important contributor to public health in the $19^{\text {th }}$ and $20^{\text {th }}$ centuries. ${ }^{10}$
The creation of the NIH during President Roosevelt's administration was spearheaded by Vannevar Bush, then director of the Office of Science and Technology. ${ }^{1}$ As the scientific foundation of dentistry became more robust, the profession of dentistry gained more credibility as a profession. The federal investment in dental research enabled dentistry to progress from an apprentice-based profession to one based in science, fueled by academic dentistry and industry research. As dental practitioners gained respect, research-intensive dental schools emerged to make a significant investment in discovery science, reflecting the research missions of their parent universities. In 1948, President Truman signed a law creating the National Institute of Dental Research (NIDR; later NIDCR), which eventually led to a partnership with academic dental institutions. This partnership rapidly advanced our understanding of the role of environmental and genetic factors in craniofacial disease.

Over the years, collaboration between the NIDCR and the academic community ushered in major investments in genomic sciences and its application to orofacial disease as well as providing new therapeutic avenues for some of the more common dental disease such as dental caries and periodontal disease. ${ }^{1}$ Moreover, advances in dental research have contributed significantly to our understanding of the impact of oral disease on overall health. Technology that has enabled deep interrogation of the genome has revealed gene loci associated with infectious and complex human diseases. As our understanding of the genetic basis in complex human diseases continues to emerge, the investment in discovery science that 
has served the profession since its inception will take on even greater significance in the years to come..$^{10,11}$

\section{Future of the Academic Dental Workforce}

The ability to sustain dentistry as a sciencebased discipline depends on the ability of dentistscientists to conduct the discovery science needed to impact the future of dental, oral, and craniofacial research. Unfortunately, as D'Souza and Colombo explain, the uncertainty of research support of dentist-scientists, increasing financial constraints on dental school budgets, and academic and clinical demands on faculty imperil the future pipeline of trainees and jeopardize the future of discovery science that will advance the dental profession. ${ }^{2}$ This concern is further reflected in the apparent lack of competitiveness of dentist-scientists. Of the 20,000-biomedical research studies funded by NIH in 2010, dentist-scientists were among the lowest number of NIH-funded investigators.

Moreover, there continues to be a steady decline in the success rate of early career dentistscientists. ${ }^{2}$ Submission of research grant applications from dentist-scientists between the ages of 31 and 40 continues to decline, while the success rate is highest for dentist-scientists in the 51-60 age group. ${ }^{12,13}$ Strategies designed to improve the competitiveness of dentist-scientists and minimize the attrition rate need to be considered, along with increasing the pool of experienced mentors and role models. ${ }^{2}$ Dental schools will need to establish interdisciplinary collaborations and leverage resources in academic health centers and the other health sciences to expand scientific opportunities. More schools need to tap into curricular and developmental activities sponsored by training programs and other NIH-sponsored initiatives and be positioned to embrace the rapidly emerging technologies that will advance oral health.

\section{Dental Schools in Research Institutions}

As McCauley explains, a sustainable future for dentistry will require that dental schools become more closely aligned with the research mission of their universities and academic health centers. ${ }^{3}$ Evidence suggests there will be greater emphasis on interdisciplinary and transdisciplinary collaboration in tackling multidisciplinary health problems. There are examples, unfortunately, in which dentistry has failed to enter into scientific collaborations that might have more effectively addressed the diagnosis and treatment of dental disease. For example, much of the progress in understanding the etiology of bisphosphonate-induced osteonecrosis of the jaw was made primarily through research done in the medical community. By comparison the contributions from the dental community were much less. ${ }^{3,15}$ Given what we know about the importance of collaboration in alleviating the burden of disease, developing a sustainable partnership between dentists and primary care physicians takes on even greater significance. Unfortunately, similar interdisciplinary collaborations in immunology, cancer research, and microbiology have yet to develop at the level needed to more effectively address common disease mechanisms.

Another example in which interdisciplinary collaboration will likely be more effective is addressing the abnormal craniofacial development that is a sequela of the Zika virus infection. ${ }^{3,16}$ Understanding the pathogens of this disorder will require the collaboration of virologists, entomologists, and craniofacial developmental biologists to develop an effective therapy for the sequela caused by infection with the Zika virus. Given dentistry's historical strength in infectious diseases and craniofacial developmental biology, collaboration between dentist-scientists and other health professionals might enable the more rapid deployment of the necessary expertise required to prevent and/or cure this disease.

With less than a third of dental schools embedded in research-intensive universities, the ability to meet such challenges will likely delay convening the diverse teams of collaborators needed to tackle complex diseases and improve patient care. ${ }^{3}$ If dental schools hope to meaningfully contribute to the health and welfare of patients, they need to consider coming into greater alignment with their universities and academic health centers by contributing to the educational, scientific, and patient care missions of the university and health sciences. Failure to do so will further isolate dentistry from the broader university community and other health professions and minimize its influence on health care reform. To be successful, dentistry must be part of interdisciplinary and transdisciplinary organizations if the profession is to play a meaningful role in health care reform. With an increased emphasis on translational research, the path to discovery will be greatly acceler- 
ated. Diversifying sources of research funding will be necessary to remain flexible in times of funding uncertainty, and partnering with other health professions can only be achieved if dentistry is viewed as a competitive contributor and partner. ${ }^{17}$

\section{Expanding the Scope of Dental Practice}

There is ample evidence to suggest that expanding the scope of dental practice will enhance patients' overall health. ${ }^{17,18}$ This expansion could be accomplished, as explained by Lamster and Myers-Wright, by bringing dental practice into closer alignment with the larger health care environment by screening for conditions that can negatively impact oral health while placing emphasis on educating patients to modify lifestyle behavior to improve overall health. ${ }^{4}$ Screening for disease that can affect both oral and general health is an unrealized opportunity for dentists. An emerging field of periodontal medicine is focusing on the effects of periodontal infection/inflammation on distant organs and tissues. As more of the data accumulate, this development has long-term implications for the future of dentistry and provides support for expanding the scope of dental practice. ${ }^{19}$

Screening for non-communicable diseases such as coronary vascular disease, hypertension, and diabetes mellitus, particularly among patients at risk for developing these conditions, would be an invaluable service to patients. ${ }^{4}$ The dental practitioner would be obligated to provide this information to patients who might otherwise be unaware of these conditions. With a greater emphasis on prevention, there are also opportunities to play an active role in reducing the risk of disease such as oral cancer and obesity by encouraging tobacco cessation activities and nutrition counseling. The expansion of the scope of dental practice proposed by Lamster and Myers-Wright would position the dental profession to contribute to health care reform, interprofessional education, and collaborative practice. It would also place greater emphasis on health promotion and health maintenance and would impact the broader patient care community, while reaffirming the profession's respect for all patients and enhancing dentists' role in the broader community including patients and their families. It is time to put the concept of a close relationship between dentistry and medicine into practice and have the dental profession play a direct role in maintaining the overall health of patients. There is every reason to believe doing so will improve both general and oral health outcomes. ${ }^{19-22}$

\section{Research and Discovery Science}

The 1995 Institute of Medicine report on the future of dentistry recommended dental schools expand their research capacity. ${ }^{23}$ To date, however, as explained by Polverini and Krebsbach, little progress has been made. ${ }^{5}$ A steady decline in the number of dental school faculty members who are successfully competing for research funds along with a decline in research support and a lack of competitiveness of dentist-scientists has contributed to stagnation in developing and sustaining a competitive research environment. It is essential that dental students come to appreciate how research adds value to their education if dental schools hope to train dental practitioners that understand how research translates into better patient care. It is imperative that the drive for innovation and creativity serves as a catalyst for initiating new models of dental education. Indeed, generating and analyzing the evidence that results from exploring new models of education aimed at alleviating the burden of inadequate care in underserved communities, advancing oral health through innovative policy initiatives, or exploring how interprofessional practice might change the practice environment are as important as the science conducted by the bench researcher or clinical investigator. It is essential that dental schools determine where they can best contribute not only to the research mission of their own university, but also to the continued advancement of the dental profession. As health care reform continues to take shape, the rapidly changing landscape will have a major impact on the practice of dentistry.

As the personalized health care environment evolves, dentistry will also need to take a more prospective approach to health care. ${ }^{5,23}$ As new technologies and devices are developed to facilitate chairside diagnosis, dental schools will need to provide students with the most up-to-date knowledge and skills needed to focus their attention on disease risk, predict disease onset with accuracy and reliability, and intervene early to halt disease progression. ${ }^{24} \mathrm{By}$ integrating research and discovery into dental curricula and by providing students with opportunities to directly participate in research, dental schools will 
enable practitioners to stay relevant and up-to-date and be better prepared to meet the challenges of the evolving health care environment.

While there has been progress in integrating the clinical and basic sciences and providing research experiences for dental students at many schools, this paradigm is not universal; and a greater emphasis on collaborative, interdisciplinary learning should prompt dental schools to take a more progressive approach to health science education and practice. ${ }^{25-27}$ Most dental educators would agree that experiential learning in community-based settings enhances a student's understanding and appreciation of the environmental, psychosocial, and cultural determinants of oral health. One could make a similar assertion that participation in research and scholarship by students is an essential experiential learning opportunity. ${ }^{28}$ If dental schools are unwilling or unable to meet this responsibility, the profession they serve runs the risk of reverting to its apprentice-based origins and mortgaging its future to other health care disciplines that may not have the best interests of the dental profession in mind. A revisionist stance and the de facto policies that support this alternative future represent the biggest threat to dentistry as a profession. As health care reform evolves, the health care system will shift its focus from disease management to disease prevention and health promotion. Although our current reductionist approach to dental practice has proven helpful in managing infectious diseases such as dental caries, it has been far less effective in managing more complex chronic diseases such as periodontal disease. ${ }^{29}$

Our genetic makeup, our environment and lifestyle choices, and the availability of care are factors that determine our risk for disease. ${ }^{5}$ Providing patients with the right care at the right time that results in a measurable improvement in health outcomes at a lower cost will define personalized oral health care. ${ }^{30}$ To be successful in this new health care environment, oral health care professionals will need to be conversant with the emerging sciences of genomic medicine, bio- and health informatics, and health policy and be knowledgeable about the power and limitation of the emerging "omics" technologies. ${ }^{31-34}$

Contrary to the clear trends that will define future health care, the current trajectory of dental education continues its primary focus on restorative care and a practice environment that is detached and isolated from the other health professions. How will future oral health care professionals be prepared to be effective and collaborative partners in the total health of our population? An important first step is to demand these important points of emphasis in all dental schools. We must continue and, in fact, increase our investment in discovery science that will reshape the practice of dentistry. Ongoing evaluation of existing knowledge domains and competencies will require development of an innovative educational agenda that will serve to strengthen scholarship and promote innovation. The 1926 Gies report argued that dentistry should be considered an integral member of the university community and should strive to attain the highest level of scholarly excellence. ${ }^{35}$ That need continues today.

In the future, oral health care professionals will use genomic data to assess risk to determine how best to help their patients make informed decisions about their care. ${ }^{1,5}$ While there are several single gene disorders that affect the orofacial structures, as genomic medicine continues to evolve, a much more complex genetic basis for many of the most common dental diseases will no doubt be revealed. Teams of health care providers will be a defining feature of the personalized health care environment. While most dentists may believe that genomic medicine is peripheral to their practice, the ability to understand the power and limitations of genetic testing should be an important part of the oral health care professional's toolbox. ${ }^{36-38}$ Future dental practitioners will only be viewed as valued partners in a personalized health care environment when dental education places a greater emphasis on disease treatment and prevention. As globalization of health care becomes more prevalent in the developing world, dental schools will need to provide students with a deeper understand of the scope of untreated oral disease and lack of access to care in the developing world. ${ }^{39-42}$ Big data analytics will improve efficiencies in health care delivery and provide much-needed insight into evidence-based practice through data analytics, information technology, and bioinformatics. ${ }^{43-45}$ An understanding of the complexity of biological systems will be facilitated by the emerging field of systems biology, ${ }^{46}$ and disciplines such as tissue engineering and stem cell biology will lead to innovations in disease diagnosis and treatment. ${ }^{33}$ Collaborations among university-based researchers, the dental industry, and the pharmaceutical industry have led to advances in 3D imaging and 3D printing, new biomaterials for dental implants, intraoral scanning devices, computer-assisted design/computer-assisted manufacturing (CAD/CAM) 
technologies for onsite fabrication of a wide range of dental tissues, and the development of biologicals to aid in the treatment of periodontal disease and to accelerate bone regeneration.

\section{Conclusion}

The dental graduate of 2040 will face new and complex challenges. Chief among them will be the rapidly changing scientific landscape and the impact it will have on dental education and the practice environment. Several predicted outcomes and potential solutions have been outlined in this summary. From precision medicine, to the learning health care system, to global health care, to the daily use of advanced technologies, all represent major challenges to our current dental education programs and practice environments. Despite all the warning signs indicating how the changing scientific and health care landscape will dramatically affect dental education and the dental profession, there is little evidence that dental schools have been willing to reconsider their research and educational priorities and clinical practice objectives. Until dental educators and the practicing community come to grips with these challenges, this persistent attitude of complacency will likely be at the dental profession's peril. We are at a tipping point in the oral health sciences, dental education, and dental practice. While we search for solutions to current and future challenges, economic uncertainty continues to limit research dollars desperately needed to invest in the future of dental research. Dental education must continue to search for a new direction in a health care environment that is uncertain and unpredictable.

\section{Editor's Disclosure}

This article is published as part of a special project that was conducted independently of the American Dental Education Association (ADEA). Manuscripts were reviewed by the project's directors and the coordinators of the project's sections and were assessed for general content and formatting by the editorial staff. Any opinions expressed are those of the authors and do not necessarily represent the Journal of Dental Education or ADEA.

\section{REFERENCES}

1. Slavkin HC. The impact of research on the future of dental education: how research and innovation shape dental education and the dental profession. J Dent Educ 2017;81(9 Suppl):eS108-27.
2. D'Souza RN, Colombo J. How research training will shape the future of dental, oral, and craniofacial research. J Dent Educ 2017;81(9 Suppl):eS73-82.

3. McCauley LK. The future of dental schools in research universities and academic health centers. J Dent Educ 2017;81(9 Suppl):eS91-6.

4. Lamster IB, Myers-Wright N. Oral health care in the future: expansion of the scope of dental practice to improve health. J Dent Educ 2017;81(9 Suppl):eS83-90.

5. Polverini PJ, Krebsbach PH. Research and discovery science and the future of dental education and practice. J Dent Educ 2017;81(9 Suppl):eS97-107.

6. Hoffmann-Axthelm W. History of dentistry. Chicago: Quintessence Pub. Co., 1981.

7. McCluggage RW. A history of the American Dental Association: a century of health service. Chicago: American Dental Association, 1959.

8. Weinberger BW. An introduction to the history of dentistry. St. Louis: C.V. Mosby Co., 1948.

9. Guerini V, National Dental Association. A history of dentistry from the most ancient times until the end of the eighteenth century. Philadelphia: Lea \& Febiger, 1909.

10. Gutmann JL. The evolution of America's scientific advancements in dentistry in the past 150 years. J Am Dent Assoc 2009;140(Suppl 1):8S-15S.

11. Slavkin HC. Evolution of the scientific basis for dentistry and its impact on dental education: past, present, and future. J Dent Educ 2012;76(1):28-35.

12. National Institutes of Health Physician-Scientist Workforce Working Group report. Updated 2014. At: acd. od.nih.gov/psw.htm. Accessed 2 Dec. 2016.

13. National Institutes of Health Biomedical Research Workforce Working Group report. Updated 2012. At: acd. od.nih.gov/biomedical_research_wgreport.pdf. Accessed 2 Dec. 2016.

14. D'Souza R, Embree M, Myers J, et al. Our essential and endangered dentist-scientist workforce. J Dent Res 2016;2(1):3.

15. Migliorati CA, Siegel MA, Elting LS. Bisphosphonateassociated osteonecrosis: a long-term complication of bisphosphonate treatment. Lancet Oncol 2006;7(6): 508-14.

16. Plourde AR, Bloch EM. A literature review of zika virus. Emerg Infect Dis 2016;22(7):1185-92.

17. Lutfiyya MN, Brandt BF, Cerra F. Reflections from the intersection of health professions education and clinical practice: the state of the science of interprofessional education and collaborative practice. J Assoc Am Med Coll 2016;91(6):766-71.

18. Hall KL, Olster DH, Stipelman BA, Vogel AL. News from NIH: resources for team-based research to more effectively address complex public health problems. Transl Behav Med 2012;2(4):373-5.

19. Greenberg BL, Glick M. Assessing systemic disease risk in a dental setting: a public health perspective. Dent Clin North Am 2012;56(4):863-74.

20. Genco RJ, Genco FD. Common risk factors in the management of periodontal and associated systemic diseases: the dental setting and interprofessional collaboration. J Evid Based Dent Pract 2014;14(Suppl):4-16. 
21. Lalla E, Kunzel C, Burkett S, et al. Identification of unrecognized diabetes and pre-diabetes in a dental setting. J Dent Res 2011;90(7):855-60.

22. Lalla E, Cheng B, Kunzel C, et al. Dental findings and identification of undiagnosed hyperglycemia. J Dent Res 2013;92(10):888-92.

23. Field MJ, ed. Dental education at the crossroads: challenges and change. An Institute of Medicine Report. Washington, DC: National Academy Press, 1995.

24. Polverini PJ. A curriculum for the new dental practitioner: preparing dentists for a prospective oral health care environment. Am J Public Health 2012;102(2):e1-3.

25. Snyderman R, Yoediono Z. Prospective health care and the role of academic medicine: lead, follow, or get out of the way. J Assoc Am Med Coll 2008;83(8):707-14.

26. Elangovan S, Venugopalan SR, Srinivasan S, et al. Integration of basic-clinical sciences, PBL, CBL, and IPE in U.S. dental schools' curricula and a proposed integrated curriculum model for the future. J Dent Educ 2016;80(3):281-90.

27. Nadershahi NA, Bender DJ, Beck L, Alexander S. A case study on development of an integrated, multidisciplinary dental curriculum. J Dent Educ 2013;77(6):679-87.

28. Doherty EH, Karimbux NY, Kugel G. Creation and initial outcomes of a selective four-year research program for predoctoral dental students. J Dent Educ 2016;80(12):1405-12.

29. Ginsburg GS, Willard HF. Genomic and personalized medicine: foundations and applications. J Lab Clin Med 2009;154(6):277-87.

30. Nash DA. A path toward stagnation and the eventual decline of dental education and dentistry. Gen Dent 2014;62(5):9-10.

31. Ahn AC, Tewari M, Poon CS, Phillips RS. The limits of reductionism in medicine: could systems biology offer an alternative? PLoS Med 2006;3(6):e208.

32. Snyderman R. Personalized health care: from theory to practice. Biotech J 2012;7(8):973-9.

33. Baum BJ, Mooney DJ. The impact of tissue engineering on dentistry. J Am Dent Assoc 2000;131(3):309-18.
34. Rotroff DM, Motsinger-Reif AA. Embracing integrative multiomics approaches. Int J Genomics 2016;17(1):59-85.

35. Gies WJ. Dental education in the United States and Canada: a report to the Carnegie Foundation for the Advancement of Teaching. New York: Carnegie Foundation, 1926.

36. Johnson L, Genco RJ, Damsky C, et al. Genetics and its implications for clinical dental practice and education: report of panel 3 of the Macy study. J Dent Educ 2008;72(2 Suppl):86-94.

37. Eng G, Chen A, Vess T, Ginsburg GS. Genome technologies and personalized dental medicine. Oral Dis 2012; 18(3):223-35.

38. Williams SD, Hughes TE, Adler CJ, et al. Epigenetics: a new frontier in dentistry. Austr Dent J 2014;59(Suppl 1): 23-33.

39. Jin LJ, Lamster IB, Greenspan JS, et al. Global burden of oral diseases: emerging concepts, management, and interplay with systemic health. Oral Dis 2016;22(7): 609-19.

40. Williams DM. Global oral health inequalities: the research agenda. J Dent Res 2011;90(5):549-51.

41. Sgan-Cohen HD, Evans RW, Whelton H, et al. IADR global oral health inequalities research agenda (IADRGOHIRA): a call to action. J Dent Res 2013;92(3):209-11.

42. Velji A. Education for global oral health: progress in improving awareness and defining competencies. J Dent Educ 2015;79(4):351-2.

43. Costa FF. Big data in biomedicine. Drug Discov Today 2014;19(4):433-40.

44. Peters SG, Khan MA. Electronic health records: current and future use. J Comp Eff Res 2014;3(5):515-22.

45. Raghupathi W, Raghupathi V. Big data analytics in health care: promise and potential. Health Inform Sci Syst 2014;2:3

46. Hood L. Systems biology and p4 medicine: past, present, and future. Rambam Maimonides Med J 2013;4(2):e0012. 